\title{
Capstone Design: Sculpture and Structure
}

\author{
Roy McGrann, Gary Mackiewicz, Jacquelyn Walsh, \\ Katherine Williams, Jill Griffin/Yvonne Hobbs/and \\ Margaret Crocker
}

\author{
Binghamton University / Sculptor /The Discovery Center
}

\begin{abstract}
Obtaining funding for senior design projects can be a challenge. This paper presents an example of a community and university project for which the funding was obtained from a charitable foundation. The project was successfully completed as one of the projects in the interdisciplinary capstone design course at Binghamton University (SUNY).

The Discovery Center, which is a hands-on children's museum in Binghamton, NY, commissioned an outdoor sculpture from a local sculptor, Yvonne Hobbs. In conjunction with the Mechanical Engineering Department at Binghamton University, funding was received through a grant from the Marilyn Gaddis Rose and Stephen David Ross University and Community Projects Fund. Mechanical engineering students performed the work as part of their engineering design course, as well as assisted students from the Art Department of Binghamton University with the fabrication. The mechanical engineering students were selected for the project because they were familiar with the computer-aided engineering tools Pro/Engineer ${ }^{\mathrm{TM}}$ and Pro/Mechanica ${ }^{\mathrm{TM}}$. These software tools were used to perform the design of the framework for the sculpture.
\end{abstract}

The engineering students were required to ascertain the sculptor's desires and create a Pro/Engineer ${ }^{\mathrm{TM}}$ solid model of the sculpture from the artist's scale model. They then designed and analyzed the frame and foundation and selected materials for both the frame and surfaces. Significant testing of various material combinations was performed.

The sculpture was completed in September 2004. President DeFleur of Binghamton University dedicated it on 1 October 2004. The incorporation of a senior capstone design course into the proposal to obtain funding for a community project is one of the unique features of this project. Also interesting is the inclusion of students from both the School of Engineering and the Liberal Arts and Sciences College.

\section{Introduction}

The Capstone Design Course

A capstone design project that includes the fabrication of a physical deliverable is a valuable experience for young engineers. For many students it is their first interaction with 
customer or client expectations and with subcontractors and skilled technicians. In addition to the technical design work that the engineering students have been studying for several years, the students' can also gain a first experience with quotes, requisitions, purchase orders, technical salespersons, delivery constraints, and budget overruns. The participation of undergraduate engineering students in this design and fabrication process is a valuable transition to the marketplace where these experiences are commonplace.

In the Thomas J. Watson School of Engineering and Applied Science at Binghamton University (State University of New York), the capstone design project is a two-semester, interdisciplinary design course for which four credit hours are earned each semester. There are five departments that comprise the Watson School: Bioengineering (BE), Computer Science (CS), Electrical and Computer Engineering (ECE), Industrial and Systems Engineering (ISE), and Mechanical Engineering (ME). The course is required of all ECE and ME students. In addition, BE, CS, and ISE students can enroll in the capstone design course sequence in lieu of specialized capstone design courses in those departments. BE, CS, and ISE students are recruited when projects appropriate to those disciplines are available.

The faculty involved in the course includes an instructor-of-record who is responsible for coordinating the grading, scheduling of formal presentations and financing for all the design projects. In addition, another faculty member advises each project. This faculty advisor is responsible for interacting with the project sponsor and the students. The instructor-of-record also assists and directs these faculty advisors.

Based on the source of funding, there are four major types of interdisciplinary design projects. First, there are university-sponsored projects that require additional fundraising activities from the students. These projects are typically student competitions that are established by engineering professional societies. Examples from recent years are Mini-Baha Car and Super-Mileage Vehicle Competitions (SAE), Micromouse Competition (IEEE), and Mine Madness (ASME). The second type of project includes those sponsored by individual faculty. These projects often involve design and fabrication of devices for use in research or teaching activities. Some examples are an electrically controlled fixture for a microscope and an autonomous robotics laboratory that can be performed using an Internet connection and webcam. The third type of project is a student-funded project. A group of students can propose a project if they can provide their own funding and have a project that satisfies the course requirements. If these conditions are met and the group can recruit a faculty advisor, then the project will be approved.

However, the fourth type of project includes most of the projects in the capstone design course. These are projects that are sponsored by local industry, business, or other enterprise. Local industries that have sponsored projects include Lockheed-Martin, BAE SYSTEMS Controls, Raymond Corporation, and BorgWarner, Inc. Many charitable, service, and not-forprofit organizations have also requested projects: examples are St. Joseph's Rehabilitation Hospital (Corning, NY), Special People in Northeast (Philadelphia, PA), and the SPCA. Funding from charitable and service organizations is often very limited. The case study presented in this paper describing the project with a local children's museum, the Discovery Center, falls into this fourth category. 
During the first two weeks of the fall semester, students who are enrolled in the capstone design course are given the list of projects for that academic year. They are asked to select three projects on which they would like to work, ranking their choices first to third. They are also asked to list any special skills, experiences, and interests that they think are relevant to the projects. Examples of skills are wiring, electrical fabrication, amateur radio, and welding. Relevant experiences often are internship or summer work. Student interests that have been listed include robotics, manufacturing, and architecture. Based on these choices and the skills required for the projects, the instructor assigns the students to project teams. Note: students do not always work on one of the three projects they have chosen.

\section{The Discovery Center}

The Discovery Center of the Southern Tier (www.thediscoverycenter.org) is a not-for-profit, hands-on interactive museum for children and their families in Binghamton, NY. The Discovery Center is part of the national network of the Association of Children's Museums (ACM). As the brochure for the center puts it: "The mission of the Discovery Center... is to contribute to the development of the intellectual, physical and emotional well being of the children of the regional community. Our exhibits and programs engage the senses, challenge the mind, ignite the imagination and offer a diverse framework for discovery in the arts, the sciences and humanities."

Permanent exhibits in the 22,500 square foot museum include: the "Littlest" Giant Market, an A-10 flight simulator, and an air traffic control tower. A full-size fire truck is available

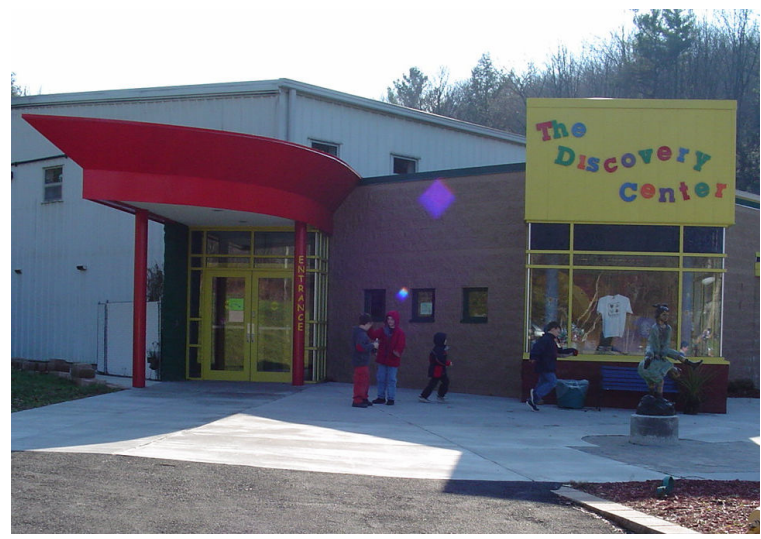

Figure 1. Discovery Center (Front Entrance) to explore. There is an Action News television studio set-up, complete with a video monitor and weather maps. In addition, there is Studio 60 where children can create their own drawings.

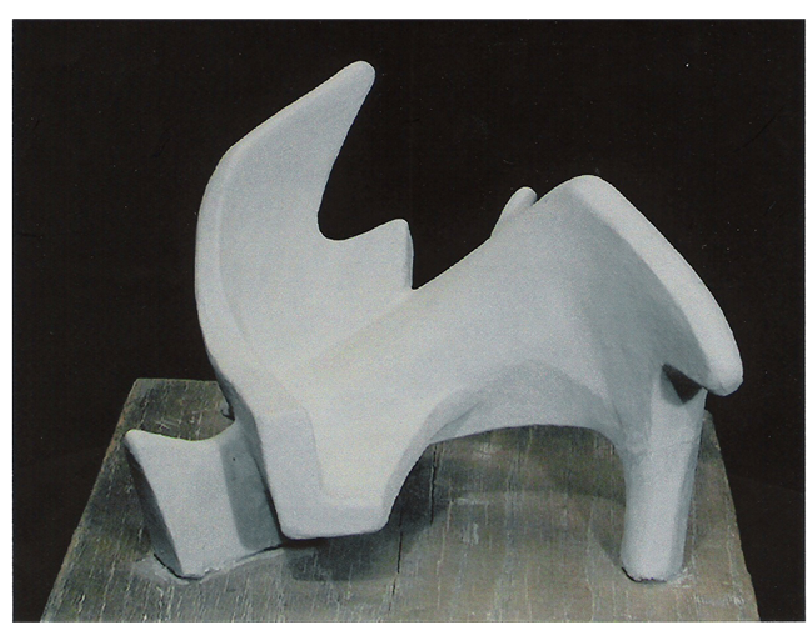

Figure 2. Model of DON'T PASS ME BY (Scale model: $1 / 6$ size)
Educational programs, such as Sensational Science and Summer Artsploration Camp, are aimed at Pre-Kindergarten through $5^{\text {th }}$ Grade children.

\section{The Sculpture}

An outdoor sculpture was commissioned from artist Yvonne Hobbs to be placed at the front entrance of the Discovery Center. She named the sculpture "Don't Pass Me By." The sculpture is intended to encourage children who are visiting the Center climb on it - a symbol of the mission of the museum, which is hands-on experience. A working model of the

Proceedings of the 2005 American Society for Engineering Education Annual Conference and Exposition Copyright $($ 2005, American Society for Engineering Education 
sculpture is shown in Figure 2. The actual sculpture was expected to be roughly $6 \mathrm{ft} . \mathrm{x} 5 \mathrm{ft} .6 \mathrm{in} . \mathrm{x}$ $4 \mathrm{ft} .(\mathrm{w} \times 1 \times \mathrm{h})$.

In the spring of 2003, the Executive Director of the Discovery Center approached the administration of the Watson School about the possibility of a cooperative project to fabricate the outdoor sculpture involving structural design by engineering students and aesthetic design by art students. The project would be one of the capstone design projects.

The Marilyn Gaddis Rose and Stephen David Ross University and Community Projects Fund Funding for the design, analysis and fabrication of the sculpture would be acquired through grants. A grant proposal was submitted to the Marilyn Gaddis Rose and Stephen David Ross University and Community Projects Fund of the Binghamton University Foundation (roserossfund.binghamton.edu). The Rose/Ross Fund was "established in 1998 to encourage creative and innovative collaboration and cooperation among Binghamton University faculty, staff and students with local arts, cultural, animal welfare, environmental and other service organizations to benefit and enhance the greater Broome County community and its residents." "Grants are awarded based on the following priorities: promotion of collaboration and cooperation between University and community groups; innovative use of the talents and resources of project partners; demonstrated commitment to the use of existing funds or to obtaining matching funds; [and] significant, enduring and positive difference in the quality of life in the community." 3 The grant was approved in May 2003 with funding commencing in July 2003.

\section{The Design Team}

At the beginning of the Fall 2003 semester, the project was included on the list from which students chose their projects. Three mechanical engineering students were selected for the project: two women and one man. Two of the students were selected based on their skills in computer-aided design and analysis (finite element) using the software Pro/Engineer ${ }^{\mathrm{TM}}$ and Pro/Mechanica ${ }^{\mathrm{TM}}$. Also, one of these students had an interest and course work in art and architecture. The third student is enrolled in the 4/1 combined BSME/MBA program. In addition to the three engineering students, one student from the Art Department of the liberal arts college at Binghamton University (Harper College) was brought into the team at the end of the fall semester. This group comprised the student design team. The team met weekly with the sculptor, the Discovery Center Director, and the faculty advisor.

\section{Project Description}

\section{Engineering Objectives}

The task was to transform the artist's model of the sculpture into the full-sized sculpture. In discussions with the sculptor, it was decided that the sculpture would be made from some plaster/concrete type material placed on a frame. The engineering objectives of the project were twofold. The first objective was to design the frame for the structure, and the second was to determine the materials with which the sculpture would be fabricated.

Engineering Approach

The two objectives were not independent. The frame design would depend on the material selected, especially the thickness of the material that would adhere to the covering (wire 
mesh) that was attached to the frame. The approach taken to the project was to take the sculptor's scale model and create a solid model in Pro/Engineer ${ }^{\mathrm{TM}}{ }^{4}$. The solid model would then be used to determine loads due to the weight of the materials. The model would also define the envelope within which the frame would be built. Simultaneously with this task, materials would be tested and the thickness of the material that would be attached to the covering of the frame would be determined. When the thickness value was known, the frame could be designed. The design would include finite element analysis using Pro/Mechanica $^{\mathrm{TM}}$.

Engineering Analysis

\section{Solid Model}

To create the solid model, an approximate "block" model was created. The dimensions of the sculptor's scale model were determined. The model was too large for the 3-D scanner that was available, so it was decided to scale and measure dimensions from digital photographs. Two of the five views used are shown in Figure 3. A steel ruler can be seen in each photo. A grid was superimposed on each photo as shown in Figure 4 for the front view. The 3-D Cartesian

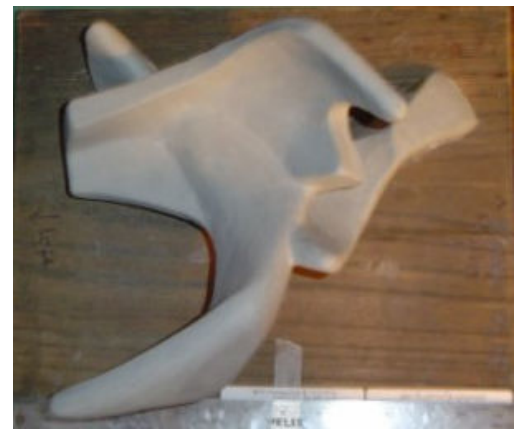

a) Top

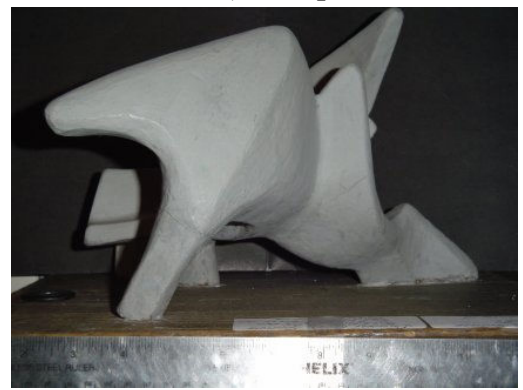

b) Front

Figure 3. Digital Photograph Views of Scale Model

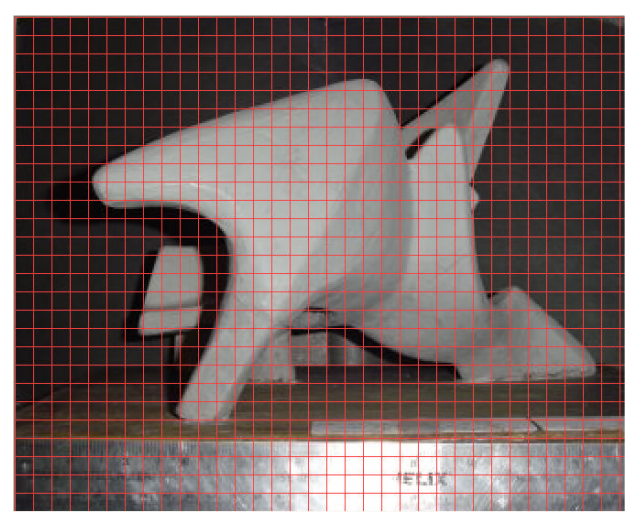

Figure 4. Superimposed Grid (Front View) coordinates of key points were determined manually from hardcopies of the photos with grids. Then, the slopes and relative positions of important features were calculated. Figure 5 shows a sample grid with some typical calculations for the same view as shown in Figure 4.

These features were then recreated as a single part in a Pro/Engineer ${ }^{\mathrm{TM}}$ solid model. While the details of the curves and surfaces of the sculptor's scale model were not exactly duplicated, the solid model was sufficiently close to the final form to be used in the engineering analysis. A screen capture of this block model is shown in Figure 6.

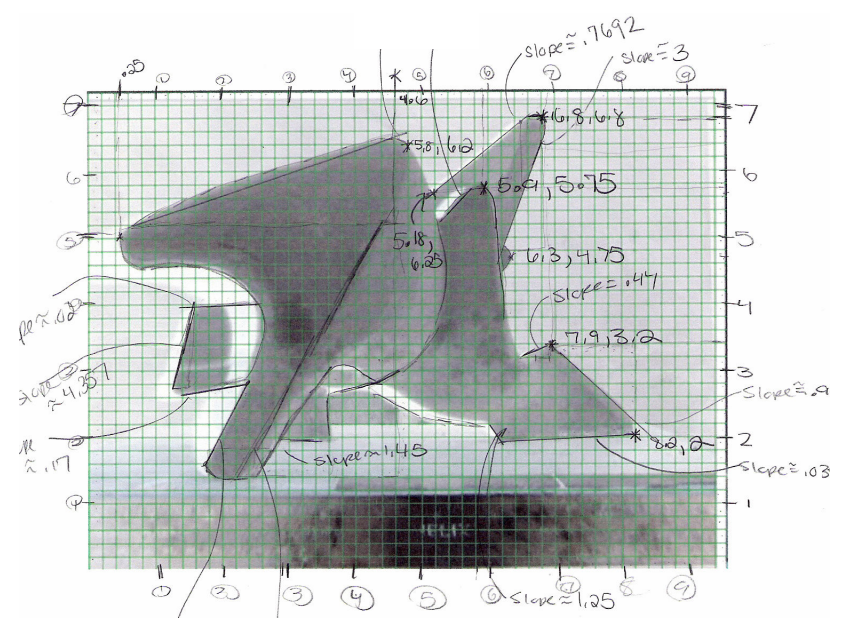

Figure 5. Sample Scaled Grid 


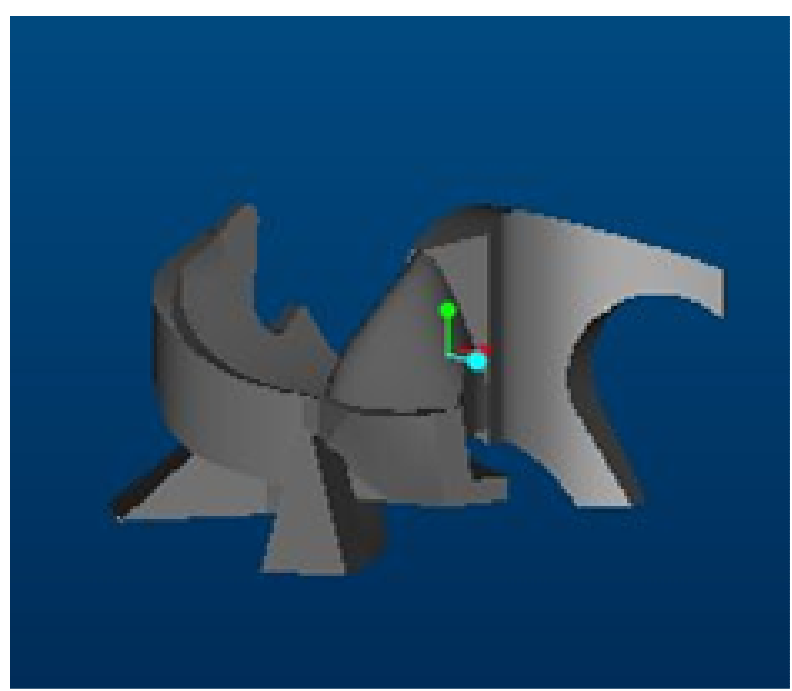

Figure 6. Screen Capture of Pro/Engineer ${ }^{\mathrm{TM}}$ Solid Model
Material Testing

Research by the design team into the types of materials that could be used for the sculpture found that the leading candidate material was Design Cast ${ }^{\circledR}$ 66. ${ }^{5}$ Design Cast is a permanent, moldable man-made stone medium. It is a synthetic, mineral based product that hardens when mixed with water and to which aggregate can be added to create the proper consistency and texture.

Testing was conducted to determine the proper mix ratios (Design-Cast 66, water, and aggregate), the adhesive strength, and the optimal thickness of material that could be applied. The density of the material was also determined. The environmental conditions in upstate New York include sub-zero to near

$100^{\circ} \mathrm{F}$, as well as significant snow and ice loads. A test matrix is shown in Table 1. Compressive strength tests were performed using a MTS Q/Test 10 Universal Test Machine. Adhesion tests were performed using these materials on various frame covering materials, including bare carbon steel, galvanized steel, and aluminum. The average of the tensile adhesive test results for the 2 in. thick blocks of material without substrates are: $2287 \mathrm{psi}$ at $32^{\circ} \mathrm{F}, 2723 \mathrm{psi}$ at $75^{\circ} \mathrm{F}$, and $2654 \mathrm{psi}$ at $90^{\circ} \mathrm{F}$.

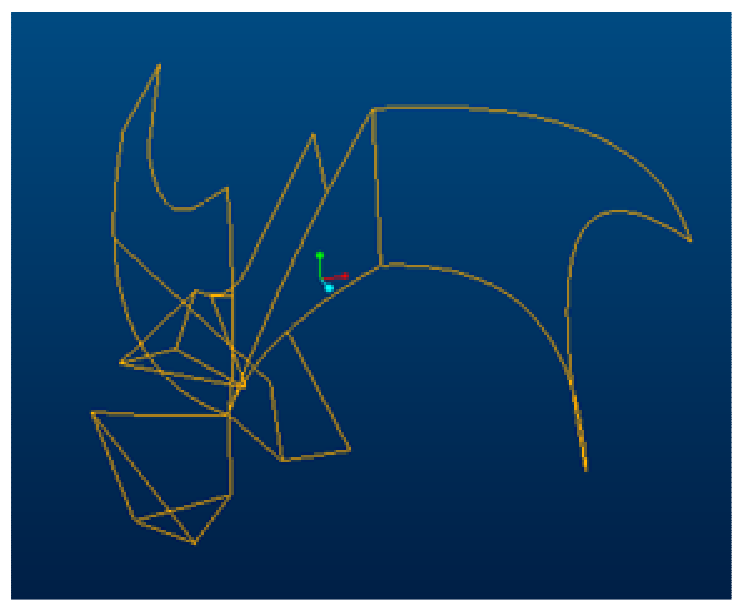

Table 1. Test Matrix for Compressive Strength

(Number of tests at condition)

\begin{tabular}{|c|c|c|}
\hline $\begin{array}{c}\text { Initial } \\
\text { Temperature } \\
\left({ }^{(} \mathrm{F}\right)\end{array}$ & \multicolumn{2}{|c|}{ Thickness } \\
\cline { 2 - 3 } & 2 in. & 3 in. \\
\hline 32 & 3 & 3 \\
\hline 75 & 3 & 3 \\
\hline 90 & 3 & 3 \\
\hline
\end{tabular}

Figure 7. Initial Frame Geometry, Pro/Mechanica ${ }^{\mathrm{TM}}$ Elements

Frame Analysis and Final Design

A Pro/Engineer ${ }^{\mathrm{TM}}$ solid model was used as an envelope to build the finite element model of the frame. An initial view of the frame geometry is shown in Figure 7. Estimated distributed loads due to the Design-Cast itself and ice and snow were used. In addition, it is hoped that children visiting the Discovery Center climb on the sculpture, so additional loads were applied. A safety factor of 10 (larger than required for playground equipment) was used in the design. 
Fabrication of the Sculpture

The frame was fabricated of 1 inch square tubing. It was then powder coated to inhibit corrosion. The frame after powder coating is shown in Figure 8. A surfacing of wire mesh was attached to the frame using metal wires. The wire mesh was shaped by hand to within an inch of the finished shape of the sculpture. Design-Cast 66 was applied to the mesh and allowed to harden. This casting material was colored to the desired finished tone. The sculptor, using sand paper, did the final shaping. Lastly, a weather-sealant was applied to the Design-Cast.

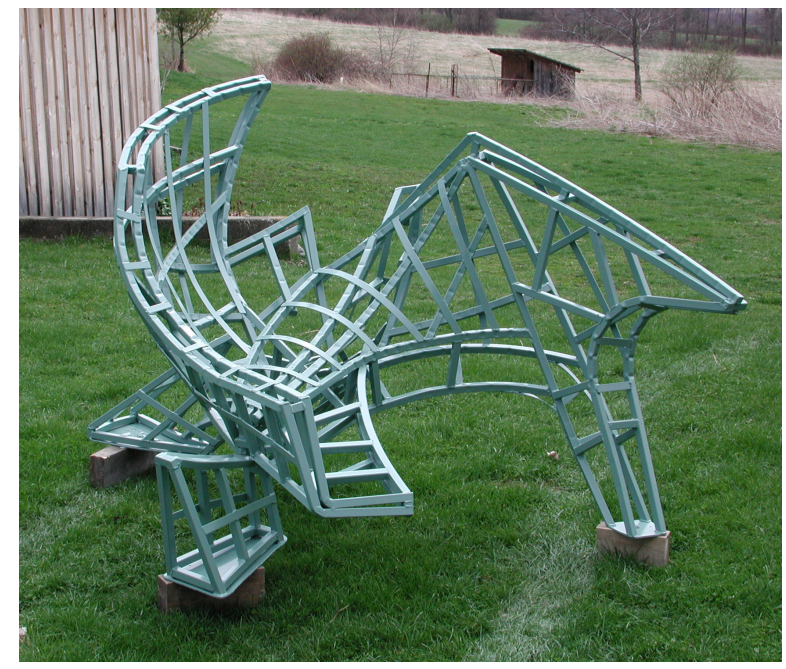

Figure 8. Frame of the Sculpture

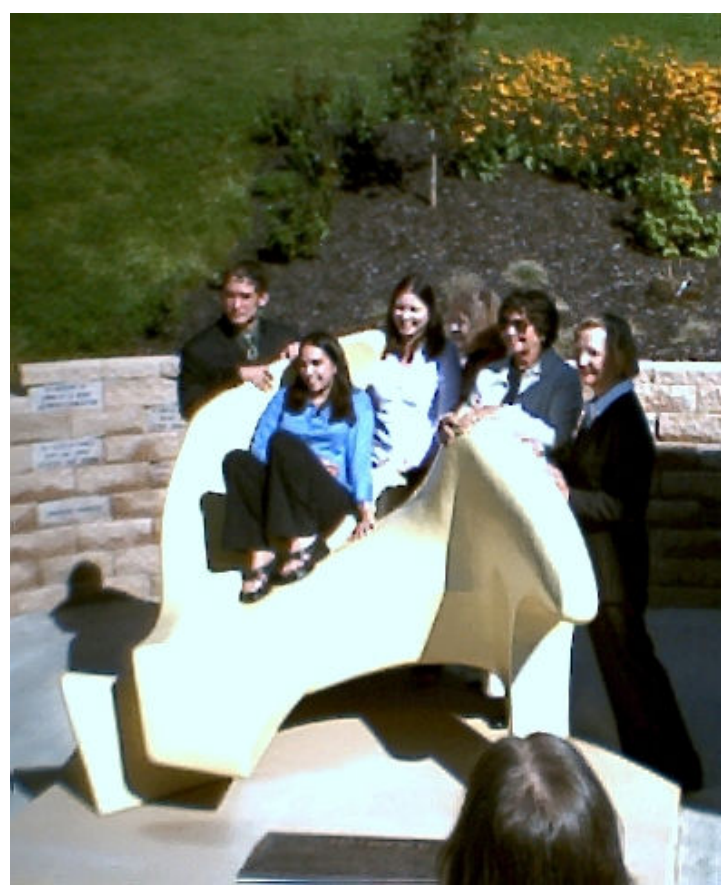

Figure 9. Dedication of the Sculpture

\section{Conclusion}

This project is an example of the successful cooperation between a community organization and the university to develop funding to provide the community with benefits that would not otherwise be available. The sculpture is shown in Figure 9. At the mid-year review of Senior Projects, the Binghamton Press \& Sun Bulletin contained a long article on this project: "Art That Asks To Be touched: BU Students, Local Artist Creating Interactive Sculpture," that emphasized the contribution by the students to the local community. ${ }^{6}$ This capstone design project is an engineering endeavor that utilizes the skills that the students have developed during their undergraduate education, such as computer-aided engineering. This project demonstrates the benefits that can be gained from "real-world" capstone design projects for students, the university, local organizations and the local community as a whole.

Bibliography

\footnotetext{
${ }^{1}$ Discovery Center brochure (also available at http://www.thediscoverycenter.org/info.htm)

${ }^{2} \mathrm{http}: / /$ roserossfund.binghamton.edu/

${ }^{3} \mathrm{http}: / /$ roserossfund.binghamton.edu/guidelines.html

${ }^{4}$ PTC, http://www.ptc.com/

${ }^{5} \mathrm{http}: / /$ www.design-cast.com/

${ }^{6}$ Binghamton Press \& Sun Bulletin, December 15, 2003. $1 \mathrm{~B}$.
} 
Biographical Information

ROY T. R. MCGRANN

Director, Engineering Design Division and Assistant Professor, Mechanical Engineering Department, Binghamton University, Binghamton, NY.

GARY MACKIEWICZ

B.S., 2004, Mechanical Engineering, Binghamton University, Binghamton, NY. Currently in graduate school at Binghamton University completing an MBA.

JACQUELYN WALSH

B.S., 2004, Mechanical Engineering, Binghamton University, Binghamton, NY. Currently employed as a Engineer I (Structural Analysis) at Northrop Grumman Corporation, Bethpage, NY.

KATHERINE WILLIAMS

B.S., 2004, Mechanical Engineering, Binghamton University, Binghamton, NY. Currently employed as an ELDP Mechanical Engineer Associate at Lockheed Maritime Sensors and Systems, Syracuse, NY.

JILL GRIFFIN

B.A., 2004, Art, Binghamton University, Binghamton, NY. Currently in graduate school in Philadelphia.

YVONNE ROBARE HOBBS

Sculptor, Nichols, NY.

MARGARET S. "POKEY" CROCKER

Executive Director, The Discovery Center, Binghamton, NY

Proceedings of the 2005 American Society for Engineering Education Annual Conference and Exposition

Copyright $@$ 2005, American Society for Engineering Education 